\title{
ENHANCEMENT OF ANTITUMOR EFFECT OF CYTOTOXIC AGENTS BY BESTATIN
}

\author{
Fuminori Abe, Kyoichi Shibuya, Junko Ashizawa, Katsutoshi Takahashi, \\ Hiroo Horinishi, Akira Matsuda, Masaaki Ishizuka, ${ }^{\dagger}$ \\ TOMIO TAKeUCHI ${ }^{\dagger}$ and Hamao UMEZAWA ${ }^{\dagger}$ \\ Research Laboratories, Pharmaceutical Division, Nippon Kayaku Co., Ltd., \\ 3-31-12 Shimo, Kita-ku, Tokyo 115, Japan \\ tInstitute of Microbial Chemistry, \\ 3-14-23 Kamiosaki, Shinagawa-ku, Tokyo 141, Japan
}

(Received for publication September 13, 1984)

\begin{abstract}
Bestatin enhanced the antitumor effects of mitomycin C, 5-fluorouracil and cis-dichlorodiammineplatinum against a syngeneic solid tumor of colon adenocarcinoma 26 in BALB/c mice. The enhancement was dependent on administration schedule. Bestatin administration after treatment with the cytotoxic agents was more effective than that made before the treatment.
\end{abstract}

Bestatin $^{1)}, N$-[(2S,3R)-3-amino-2-hydroxy-4-phenylbutanoyl]-L-leucine, has low toxicity ${ }^{2)}$, inhibits aminopeptidases $^{3)}$, binds to cell surfaces ${ }^{4,5)}$, enhances immune responses ${ }^{6 \sim 8)}$ and exhibits antitumor effect against mouse tumors $\mathrm{s}^{7,8 \sim 11}$. The effect of bestatin on the immune responses of mice and human has been studied in more detail ${ }^{12 \sim 10)}$. We here report the results obtained after examination of the effect of bestatin in enhancing the antitumor effects of cytotoxic agents such as mitomycin C, 5-fluorouracil and cis-dichlorodiammineplatinum.

\section{Materials and Methods}

Female BALB/c mice of 9 to 10 weeks old were purchased from Charles River Japan Inc. They were kept in a Sanki Kogeisha Isolack and cages, feed and other items were sterilized before use. The following agents were dissolved and sterilized by passing through a Millipore filter: bestatin (Nippon Kayaku Co., Ltd.), mitomycin C (MMC; Kyowa Hakko Kogyo Co., Ltd.), 5-fluorouracil (5-FU; Kyowa Hakko Kogyo Co., Ltd.) and cis-dichlorodiammineplatinum (CDDP; Nippon Kayaku Co., Ltd.).

Colon adenocarcinoma 26 originally provided by Dr. TsukAGoshi of Cancer Chemotherapy Center, Japanese Foundation for Cancer Research, has been maintained by successive subcutaneous transplantation to $\mathrm{BALB} / \mathrm{c}$ mice as described in the protocol of $\mathrm{NCI}$, USA ${ }^{17)}$. Hanks' balanced salt solution $(0.1 \mathrm{ml})$ containing $1 \times 10^{5}$ viable colon adenocarcinoma 26 cells was subcutaneously injected to the lateral region of mouse abdomen. Each cytotoxic agent was intravenously administered once a day on the 7 th and 8 th days after injection of the tumor cells. On the 8th day tumor growth could be seen with the naked eye. Bestatin was orally administered $(5 \mathrm{mg} / \mathrm{kg})$ on days $1 \sim 6$ or $9 \sim 14$.

The efficacy of bestatin was evaluated by comparing the survival of bestatin-administered mice with that of non-administered mice. The antitumor effect of cytotoxic agents was similarly evaluated from survival of treated and non-treated mice. The results were expressed by $\%$ of $T$ to $C(T / C)$. T and $C$ are mean survival days of bestatin or cytotoxic agent-treated mice and those of non-treated mice, respectively. In these evaluations the maximum life prolongation period was fixed at 70 days which was about 3 times longer than the survival of the non-treated mice.

\section{Results}

Effective doses of the cytotoxic agents were determined in a preliminary study, and the following 
Fig. 1. Survival rate of colon adenocarcinoma 26-transplanted BALB/c mice treated with bestatin and mitomycin $\mathrm{C}$.

1, Saline or bestatin alone; 2 MMC $(1.25 \mathrm{mg} / \mathrm{kg})$ iv on day 7 and $8 ; 3$, MMC and bestatin $(5 \mathrm{mg} /$ $\mathrm{kg}$ ) po from days 1 to $6 ; 4, \mathrm{MMC}$ and bestatin po from days 9 to 14 .

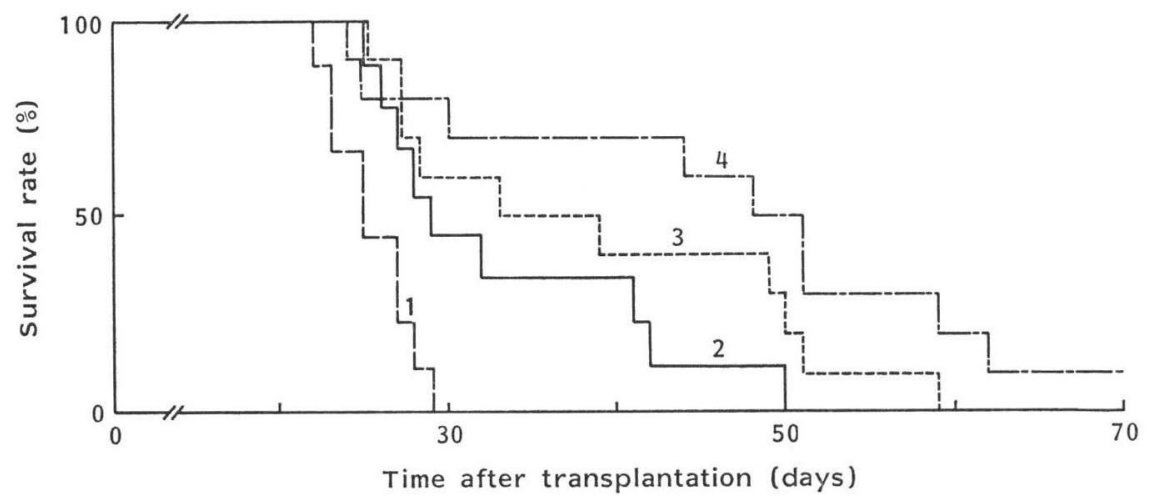

Fig. 2. Survival rate of colon adenocarcinoma 26-transplanted BALB/c mice treated with bestatin and 5-fluorouracil.

1, Saline or bestatin alone; $2,5-\mathrm{FU}(30 \mathrm{mg} / \mathrm{kg})$ iv on day 7 and $8 ; 3,5-\mathrm{FU}$ and bestatin $(5 \mathrm{mg} / \mathrm{kg})$ po from days 1 to $6 ; 4,5$-FU and bestatin po from days 9 to 14 .

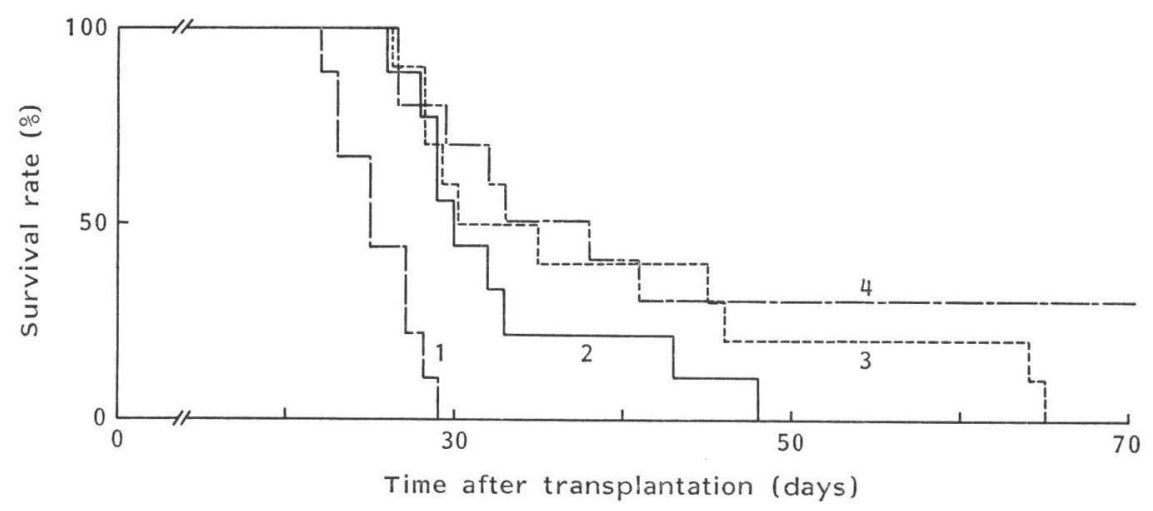

Fig. 3. Survival rate of colon adenocarcinoma 26-transplanted BALB/c mice treated with bestatin and cis-dichlorodiammineplatinum.

1, Saline or bestatin alone; 2, CDDP $(1 \mathrm{mg} / \mathrm{kg})$ iv on day 7 and $8 ; 3$, CDDP and bestatin (5 $\mathrm{mg} / \mathrm{kg}$ ) po from days 1 to $6 ; 4$, CDDP and bestatin po from days 9 to 14 .

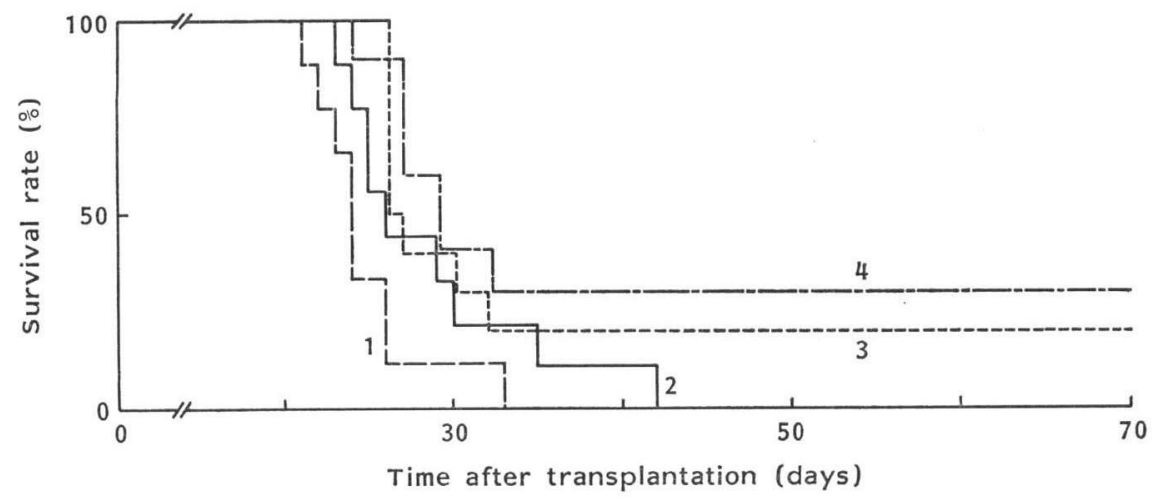


doses were used in the present study; $1.25 \mathrm{mg} / \mathrm{kg}$ for MMC, $30 \mathrm{mg} / \mathrm{kg}$ for 5 -FU and $1 \mathrm{mg} / \mathrm{kg}$ for CDDP. The doses of MMC and 5-FU were each optimum dose and the CDDP dose was suboptimum one. As reported previously bestatin given at 1.5 to $15 \mathrm{mg} / \mathrm{kg}$ enhanced immune responses ${ }^{6,7,18)}$. Bestatin was given here at $5 \mathrm{mg} / \mathrm{kg}$.

Values of T/C obtained by treatment with each cytotoxic agent alone were 131 for MMC, 130 for 5-FU and 116 for CDDP (Figs. 1, 2 and 3). No prolongation of survival of mice was observed for the group which received bestatin alone (data not shown). In the case of a combined treatment with MMC and bestatin, administration of bestatin on days $1 \sim 6$ prior to MMC administration on the 7th and 8th days gave a $\mathrm{T} / \mathrm{C}$ value of 153 (Fig. 1). In contrast, bestatin administration on days $9 \sim 14$ after MMC administration brought about a remarkable prolongation of survival, giving a $T / C$ value of 183 . In addition, no tumor was detected in one of the 10 mice of the group.

In another combined treatment using 5-FU together with bestatin, a $\mathrm{T} / \mathrm{C}$ value of 156 was obtained when bestatin was pre-administered on days $1 \sim 6$, while $\mathrm{T} / \mathrm{C}$ value was 171 when bestatin was postadministered on days $9 \sim 14$ (Fig. 2). Furthermore, no tumor could be detected in 3 of the 10 mice in the group where bestatin was post-administered.

In a combination of CDDP with bestatin, pre-administration of bestatin on days $1 \sim 6$ resulted in a $\mathrm{T} / \mathrm{C}$ value of 145 and post-administration on days $9 \sim 14$ a T/C value of 163 (Fig. 3). Two of the 10 bestatin-pre-administered mice and 3 of the 10 bestatin-post-administered mice were tumor-free. CDDP given here was at a suboptimum dose of $1 \mathrm{mg} / \mathrm{kg}$ as described above. CDDP optimum dose was $4 \mathrm{mg} /$ $\mathrm{kg}$. When CDDP was administered at the optimum dose, CDDP alone gave a T/C value of 192. Preand post-administration of bestatin in combination with CDDP gave T/C values of 216 and 210, respectively and these $\mathrm{T} / \mathrm{C}$ values were not significantly more than that (192) obtained with CDDP alone. Conclusively, bestatin was effective at the suboptimum dose rather than the optimum dose in the combined treatment with CDDP. The dose range of CDDP for exhibition of antitumor activity was relatively close to that of toxicity and care must be taken for avoiding the toxicity in application of $\mathrm{CDDP}^{12,20)}$. Taking the above results into consideration the combination of CDDP with bestatin may be a procedure to more safely apply CDDP because bestatin had much less toxicity than $\mathrm{CDDP}^{2}$.

\section{Discussion}

As previously reported ${ }^{2)}$, when a small number of cells $\left(1 \times 10^{4}\right)$ of colon adenocarcinoma 26 was subcutaneously transplanted in mice, bestatin inhibited the growth of the tumor and augmented cellmediated antitumor responses. However, bestatin did not inhibit the growth at all when a larger number of the tumor cells $\left(1 \times 10^{5}\right)$ was transplanted. Thus, we here examined the effect of bestatin in its combined treatment with a clinically useful antitumor agent against colon adenocarcinoma 26 transplanted in mice by $1 \times 10^{5}$ cells. As detailed above, bestatin was more efficacious in the combined treatment when administered after administration of an antitumor agent rather than before. These results suggest that bestatin shows a positive effect on the small number of remaining tumor cells after most of tumor cells are previously killed by action of pre-administered antitumor agents.

Bestatin restored the lowered immune responses of tumor-bearing mice ${ }^{12)}$. Bestatin also increased cfu-c (colony forming unit culture) of the bone marrow stem cells. Particularly, enhancement of recovery of the bone marrow functions of tumor-bearing mice was brought about by bestatin administration even when chemotherapy had been applied to the mice ${ }^{18)}$. Taking these facts into consideration, bestatin may be considered to exhibit combination efficacy against colon adenocarcinoma 26 by restoring bone marrow function and exhibiting host-mediated antitumor activity. 


\section{References}

1) Umezawa, H.; T. Aoyagi, H. Suda, M. Hamada \& T. Takeuchi: Bestatin, an inhibitor of aminopeptidase B produced by actinomycetes. J. Antibiotics 29: 97 99, 1976

2) Ito, K.; J. Handa, Y. Irie, T. Hagiwara, Y. Sakai, M. Hayashi, T. Sakakibara, M. Suzuki, Y. Irie, M. Horiguchi, M. Kurata, T. Machida, M. Tsubosaki, A. Matsuda \& N. Konoha: Toxicological studies on bestatin. III. Chronic toxicity test and recovery study in beagle dogs. Jpn. J. Antibiotics 36 : 3053 3193, 1983

3) Suda, H.; T. Aoyagi, T. TAKeuchi \& H. UmezAwA: Inhibition of aminopeptidase B and leucine aminopeptidase by bestatin and its stereoisomer. Arch. Biochem. Biophys. 177: 196 200, 1976

4) Aoyagi, T.; H. Suda, M. Nagai, K. Ogawa, J. Suzuki, T. Takeuchi \& H. Umezawa: Aminopeptidase activities on the surface of mammalian cells. Biochem. Biophys. Acta 452: $131 \sim 143,1976$

5) Müller, W. E. G.; D. K. Schuster, R. K. Zahn, A. Mainhof, G. Leyhausen, D. Falke, R. Koren \& H. UMEZAWA: Properties and specificity of binding sites for the immunomodulator bestatin on the surface of mammalian cells. Int. J. Immunopharmacol. 4: 393 400, 1982

6) Umezawa, H.; M. Ishizuka, T. Aoyagi \& T. Takeuchi: Enhancement of delayed-type hypersensitivity by bestatin, an inhibitor of aminopeptidase B and leucine aminopeptidase. J. Antibiotics 29: 857 859, 1976

7) Ishizuka, M.; T. Masuda, N. Kanbayashi, S. Fukasawa, T. Takeuchi, T. Aoyagi \& H. Umezawa: Effect of bestatin on mouse immune system and experimental murine tumors. J. Antibiotics 33: 642 652, 1980

8) Ishizuka, M.; J. Sato, Y. Sugryama, T. Takeuchi \& H. Umezawa: Mitogenic effect of bestatin on lymphocytes. J. Antibiotics 33: 653 662, 1980

9) Abe, F.; K. Shibuya, M. Uchida, K. Takahashi, H. Horinishi, A. Matsuda, M. Ishizuka, T. Takeuchi \& H. Umezawa: Effect of bestatin on syngeneic tumors in mice. Gann 75: 89 94, 1984

10) Tsuruo, T.; K. Naganuma, H. Iida, T. Yamori, S. Tsukagoshi \& Y. Sakurai: Inhibition of lymph node metastasis of P388 leukemia by bestatin in mice. J. Antibiotics 34: 1206 1209, 1981

11) Sonoyama, T.; N. Terata, H. Matsumoto, A. Nozaki, K. Kimura, H. Kurioka, I. Hashimoto, F. Tsunoda \& M. Kodama: Study on the antitumor effect of an inhibitor against cell surface enzyme (Bestatin). Jpn. J. Society for Cancer Therapy 17: 1264 1269, 1982

12) Bruley-Rosset, M.; I. Florentin, N. Kiger, J. Schulz \& G. Mathé: Restoration of impaired immune functions of aged animals by chronic bestatin treatment. Immunology 38: 75 83, 1979

13) Schorlemmer, H. U.; K. Bosslet \& H. H. Sedlacek: Ability of the immunomodulating dipeptide bestatin to activate cytotoxic mononuclear phagocytes. Cancer Res. $43: 4148 \sim 4153,1983$

14) Dicknite, G.; F. Kaspereit \& H. H. Sedlacek: Stimulation of cell-mediated immunity by bestatin correlates with reduction of bacterial persistence in experimental chronic Salmonella typhimurium infection. Infec. Immun. 44: 168 174, 1984

15) Blomgren, H.; L.-E. Strender \& F. Edsmyr: The influence of bestatin on the lymphoid system in the human. In Small Molecular Immunomodifiers of Microbial Origin - Fundamental and Clinical Studies of Bestatin. Ed., Umezawa, H., pp. $71 \sim 99$, Japan Sci. Soc. Press, Tokyo, 1981

16) Noma, T.; B. Klein, D. Cupissol, J. Yata \& B. Serrou: Increased sensitivity of IL2-dependent cultured $\mathrm{T}$ cells and enhancement of in vitro IL2 production by human lymphocytes treated with bestatin. Int. J. Immunopharmacol. 6: 87 92, 1984

17) Goldin, A.; J. M. Venditti, J. S. Macdonald, F. M. Muggia, J. E. Henney \& V. T. Devita: Current results of the screening program at Division of Cancer Treatment, National Cancer Institute. Eur. J. Cancer 17: 129 142, 1981

18) Ishizuka, M.; T. Aoyagi, T. Takeuchi \& H. Umezawa: Activity of bestatin: Enhancing of immune responses and antitumor effect. In Small Molecular Immunomodifiers of Microbial Origin - Fundamental and Clinical Studies of Bestatin. Ed., Umezawa, H., pp. 17 38, Japan Sci. Soc. Press, Tokyo, 1981

19) Wolpert-DeFilippes, M. K.: Antitumor activity of cis-dichlorodiammineplatinum (II). Cancer Treat. Rep. 63: $1453 \sim 1458,1979$

20) TaKahashi, K.; K. Ebihara, Y. Honda, K. Nishikawa, M. Kita, M. Oomura \& C. Shibasaki: Antitumor activity of cis-dichlorodiammineplatinum (II) and its effect on cell cycle progression. Jpn. J. Cancer Chemother. 9: $624 \sim 631,1982$ 